NBER WORKING PAPER SERIES

\title{
VOLUNTARY PUBLIC GOODS PROVISION, COALITION FORMATION, AND UNCERTAINTY
}

\author{
Nicholas E. Burger \\ Charles D. Kolstad \\ Working Paper 15543 \\ http://www.nber.org/papers/w15543 \\ NATIONAL BUREAU OF ECONOMIC RESEARCH \\ 1050 Massachusetts Avenue \\ Cambridge, MA 02138 \\ November 2009
}

\begin{abstract}
We would like to thank Mark Isaac, Marc Nerlove, Ulrich Wagner, Tobey Page, Michael Greenstone, Wayne Gray, and seminar participants at the Columbia, Harvard, NBER, Resources for the Future, the University of California at Berkeley, the University of California at Santa Barbara, and the University of Maryland for helpful comments. Gary Charness provided invaluable insights at many stages of our experimental development. However, we are responsible for all errors. Supported in part by the National Science Foundation, grant No. 0114437, and Resources for the Future. The views expressed herein are those of the author(s) and do not necessarily reflect the views of the National Bureau of Economic Research.
\end{abstract}

NBER working papers are circulated for discussion and comment purposes. They have not been peerreviewed or been subject to the review by the NBER Board of Directors that accompanies official NBER publications.

(C) 2009 by Nicholas E. Burger and Charles D. Kolstad. All rights reserved. Short sections of text, not to exceed two paragraphs, may be quoted without explicit permission provided that full credit, including (c) notice, is given to the source. 
Voluntary Public Goods Provision, Coalition Formation, and Uncertainty

Nicholas E. Burger and Charles D. Kolstad

NBER Working Paper No. 15543

November 2009

JEL No. C7,C91,C92,H23,H4,H41,Q5,Q54

\begin{abstract}
$\underline{\text { ABSTRACT }}$
The literature on voluntary provision of public goods includes recent theoretical work on the formation of voluntary coalitions to provide public goods. Theory is ambiguous on the equilibrium coalition size and contribution rates. We examine the emergence of coalitions, their size, and how uncertainty in public goods provision affects contribution levels and coalition size. We find that contributions decrease when public good returns are uncertain but increase when individuals can form a coalition to provide the good. Contrary a core theoretical result, we find that coalition size increases when the public good benefits are higher. Uncertainty has no effect on coalition size.
\end{abstract}

Nicholas E. Burger

RAND Corporation

1200 South Hayes Street

Arlington VA 22202-5050

Nicholas_Burger@rand.org

Charles D. Kolstad

Department of Economics

University of California

Santa Barbara, CA 93106

and NBER

kolstad@econ.ucsb.edu 


\section{Introduction}

Theory tells us that despite free-riding, individuals will voluntarily contribute to public goods, though at far lower levels than efficient (Bergstrom et al. 1986, Bernheim 1986, Hirschleifer 1983). Experimental evidence suggests that voluntary provision will be substantially higher than theory suggests (Ledyard 1995), though still at inefficient levels. The nascent theoretical literature on coalition formation in public goods provision ${ }^{2}$ suggests that modest increases in overall provision result from the spontaneous formation of subgroups (coalitions) of the population to jointly provide public goods. ${ }^{3}$ Furthermore, that literature suggests a relationship between coalition size and per capita benefits of the public good. However, there is ambiguity in this literature regarding which of several models of coalition formation and behavior is most appropriate. Additionally, there is debate over how uncertainty influences coalition formation and public goods provision: some suggest uncertainty serves to strengthen coalitions (Young 1994), while others argue that it weakens them (Iida 1993).

This paper seeks to provide the first joint theoretical and experimental treatment of coalitions in voluntary public good provision, quantifying the effectiveness of these coalitions in increasing public good provision. We present a simple theory of coalition formation with and without uncertainty and then test the predictions of this theory using a laboratory experiment. To the best of our knowledge, research on subgroup formation in public goods provision experiments has not used theory to directly motivate experimental design. Consequently, there

\footnotetext{
${ }^{2}$ The theoretical literature on coalition formation in public goods provision is primarily cast in the context of selfenforcing international environmental agreements for the control of global environmental problems. This literature treats each country as a single utility-maximizing agent; consequently, most work is completely equivalent to and can be interpreted as voluntary provision of public goods by individual agents. Some additional literature (primarily empirical) pertains to international monetary agreements (Iida 1993).

${ }^{3}$ This is akin to the provision of club goods except that members of the coalition (club) enjoy no more access to the benefits of the public good than do non-club members (Sandler and Tschirhart 1997).
} 
has been a disconnect between experimental and theoretical approaches to public goods provision.

Our experimental results support some theoretical predictions but call others into question. Our strongest result contradicts one of the basic conclusions of the theoretical literature - that coalition size decreases with the benefits from public good provision. Furthermore, experimental evidence suggests that uncertainty tends to decrease the provision of public goods, both when coalitions can and cannot form. Finally, although some theories argue that uncertainty will increase coalition size, while others make the opposite prediction, we find little evidence that uncertainty either increases or decreases coalition size.

In the next section of the paper we discuss the relevant literature on coalition formation in a public goods setting. In section 3 section we present a simple theoretical model of public goods provision and coalition formation, based on the model in Kolstad and Ulph (2008). The theoretical model provides certain testable hypotheses about coalition size and the role of uncertainty. In section 4 we turn to our experimental investigation, developing a model based on the established experimental literature on public goods provision, which we extended to endogenous coalition formation and uncertainty. We use the model to test the theoretically based hypotheses of behavior.

\section{Coalition Formation and the Experimental Literature}

This paper contributes to two separate but closely related literatures in economics. At the most basic level, we expand on the growing public goods provision literature in experimental economics. Although much of this literature focuses on public goods, certain topics have received less attention - two such areas are coalition formation and uncertainty. Moreover, to the 
best of our knowledge, no paper has examined these issues jointly. Second, we offer a test of the theoretical literature on coalition formation in the context of international environmental agreements, exploring competing theoretical hypotheses regarding the operation of such agreements.

\subsection{Coalition Formation}

In confronting public goods problems, a primary challenge is to develop a mechanism that coordinates actions in a mutually beneficial way. Forming a coalition is one way for agents to overcome the free-rider problem. It happens that much of the theoretical literature on coalition formation is in the context of the formation of international environmental agreements (IEA), in which countries are modeled as having a single payoff function. Leaving aside the issue of whether modeling a country with a single utility/payoff function is appropriate, the fact is that all of the results from the IEA literature can be interpreted as results for individual interacting utility maximizing agents forming coalitions to provide public goods.

When facing a global environmental problem, countries must decide whether to emit or abate pollution. Countries prefer collective abatement over independent action but have a strong incentive to free-ride on others' actions. Early work on IEAs demonstrated that a coalition mechanism can partially overcome the free-rider problem (Hoel 1992, Barrett 1994, Carraro and Siniscalco 1993). However, coalitions are unlikely to be large. If we define the marginal per capita return (MPCR) to abatement in terms of the environmental benefit from a unit of abatement, the literature can be summarized in terms of the effect of MPCR on equilibrium coalition size. If a large coalition is an equilibrium, then it must be the case that the benefits from cooperation are small (MPCR low). The higher the MPCR, the greater the incentives to 
free ride and thus the small the equilibrium coalition. Similarly, with low MPCR, the attraction of joining the coalition (versus remaining in the fringe) is stronger and a larger coalition will emerge. In other words, we are likely to see broad coalitions form only when they are least beneficial. We provide a more formal explanation in Section 3.

Another common feature of global public good problems is uncertainty. Most early research in the IEA literature considered situations in which the benefits of abatement are known. If benefits are uncertain, however, the coalition formation process may change. The literature on coalition formation under uncertainty provides ambiguous predictions. While Young (1994) suggests that uncertainty can facilitate the formation of international agreements, others, like Iida (1993), find that uncertainty hinders coalition formation. In a recent paper, Kolstad and Ulph (2008) analyze coalition formation with uncertainty and learning in a gametheoretic environment. They find that the effect of uncertainty on the optimal coalition size is ambiguous. We draw on this paper to motivate our experimental design and hypotheses, outlined in section 3 .

\subsection{Public Goods Provision in Experimental Economics}

Early experimental work on public good provision established that subjects tend to provide public goods at higher rates than predicted by Nash equilibrium theory (e.g. Marwell and Ames 1979, Kim and Walker 1984). Since that time, experimentalists have focused their attention on why subjects contribute at the rates they do and what mechanisms affect contribution rates. For instance, a common assumption was that larger groups would have more difficulty providing public goods. Instead, as Isaac and Walker (1988) demonstrated, marginal per capita return (MCPR) predominantly determines contribution levels - there is no separate 
pure group size effect. ${ }^{4}$ One possible reason for these results is that subjects are confused by the experimental setup. Andreoni (1995) explores this issue and concludes it is not a valid explanation of the divergence between theory and experiments.

More recently, there has been some research on endogenous group formation (e.g., Ehrhart and Keser 1999) wherein subjects can join or leave groups either freely or with restrictions. These studies examine how individuals that form (sub)groups provide public goods. However, much of the work in this area emphasizes different methods of matching individuals in groups (Gunnthorsdottir et al 2007, Page et al 2005). Most experiments on endogenous group formation use multi-period designs, where subjects have the opportunity to change their group affiliation over time. Page et al (2005) allow subjects to express a preference for partners in the next period based on past performance of other subjects. Ahn et al. (2008) examine entry/exit institutions for group formation but do not allow for formal agreements. Research on group size has tended to focus on how the number of subjects affects public goods provision and largely ignores the determinants of group or subgroup size. A recent exception is Charness and Yang (2007). Finally, few if any endogenous group formation experiments base their experimental design on theoretical models of group formation, such as the international agreements literature.

While the existing group formation literature investigates how individuals provide public goods in different group settings, it does not focus on formal sub-groups or coalitions per se. ${ }^{5}$ And although there is a sizeable literature on coalition formation, ${ }^{6}$ much of it is an extension of the classic two-person ultimatum/bargaining literature (e.g. Guth et al 1982) to three (or more)

\footnotetext{
${ }^{4}$ Isaac et al (1994) provide support for these findings using significantly larger groups.

${ }^{5}$ An exception is Ahn et al. (2005), which allows for sub-groups with little coordination among participants.

Moreover, this study places no constraints on the number of groups, nor are the sub-groups endowed with a specific purpose.

${ }^{6}$ Bolton and Chatterjee (1996) provide a summary of the theoretical literature on coalition formation as well as a brief overview of experimental work.
} 
persons. ${ }^{7}$ By and large, most studies do not analyze coalition formation in a large-group setting. Confining themselves to a three-person setting, ${ }^{8}$ Bolton and Chatterjee (1996) provide evidence that communication structures matter both for coalition formation and payoff distribution. Building on this and other work, Okada and Riedl (2005) find evidence that reciprocal actions strongly affect outcomes in a coalition bargaining game and that players will often choose inefficient subcoalitions, as a result. However, these coalition formation experiments deal with utility-maximizing bargains, not social outcomes or public goods.

Neither risk nor uncertainty has received significant attention in the experimental literature on public goods or coalition/bargaining games. Murnighan et al. (1988) explore the effects of risk aversion on outcomes in bargaining games. They find that while risk-averse bargainers perform better on high-stakes games, the effects are somewhat weak. In coalition games, risk aversion appears to predict coalition formation but not payoff distribution in inexperienced bargainers (Bottom et al 2000); experienced bargainers exhibit the opposite behavior. There is some evidence that uncertainty affects cooperation in public goods games. Berger and Hershey (1994) demonstrate that subjects are less likely to contribute to a public good when returns are stochastic than when returns are deterministic. In Dickinson (1998) subjects make voluntary contributions to a public good in which there is some probability that the group payoff will be zero. Dickinson finds limited evidence that uncertainty reduces individual but not group contributions. To the best of our knowledge, no one has yet examined how uncertain payoffs affect group formation.

\footnotetext{
${ }^{7}$ For a summary of bargaining, see Camerer (2003) or Roth (1996).

${ }^{8}$ As Bolton and Chatterjee point out, limiting coalition analysis to a three-person setting allows researchers to analyze the inherent complexities of having more than two people but without adding additional confounding effects.
} 


\section{Theoretical Predictions of Coalition Formation}

Let there be $\mathrm{i}=1, \ldots$, I identical individuals with unitary endowments. Each individual has two choices: spend the endowment on private consumption or allocate the endowment to public consumption. Public consumption generates less for the donor but more for the group of individuals:

$$
\Pi_{\mathrm{i}}=\left(1-\mathrm{q}_{\mathrm{i}}\right)+\gamma \mathrm{Q} \quad, \quad \mathrm{Q}=\Sigma_{\mathrm{i}} \mathrm{q}_{\mathrm{i}}
$$

Where $\mathrm{q}_{\mathrm{i}}$ is the allocation to public consumption, assumed to be discrete (either zero or one) and $\Pi_{\mathrm{i}}$ is the total payoff to i. ${ }^{9}$ The parameter $0<\gamma<1$ is the private payoff from a unit of the public good, also known in the literature as the marginal per capita return to public consumption (MPCR). Clearly, in this setting, a Nash equilibrium will involve no contribution to public consumption: $q_{i}=0$, whereas a Pareto optimal allocation will involve no private consumption: $q_{i}$ $=1 .^{10}$

We are concerned with one primary issue here: the formation of coalitions to coordinate public contributions. In particular, we will allow for the formation of a group of $\mathrm{N} \leq \mathrm{I}$ individuals which will act in concert to provide public consumption. All the members of this coalition will act the same, in the best interests of the coalition as a whole.

To formalize this notion of coalition formation, we consider a two-stage game, the first a membership game to determine coalition membership and the second a public goods contribution game to determine how much of the public good will be contributed. We assume that once membership has been determined, it is fixed for the second stage.

\footnotetext{
${ }^{9}$ The reason for choosing the discrete choice contribution mechanism (all or nothing to the public good) is to simplify the decision process for the coalition, particularly in the context of the experiment. A discrete choice for individuals translates into a discrete choice for the coalition which can be easily decided by a single vote. Continuous levels of contributions would require a more complex process for determining the coalition actions.

${ }^{10}$ This is a standard model in the literature on international environmental agreements (e.g., Kolstad and Ulph 2008), although we use somewhat different terminology.
} 
The membership game is an announcement game, in which individuals announce "in" or "out" of a single coalition. We are seeking a Nash equilibrium in announcements. Participation in the coalition is voluntary, and members cannot exclude potential entrants. After the membership of the coalition and fringe (all players not in the coalition) has been determined, the coalition acts as one, jointly deciding on an action for the entire coalition using majority rule. Many decision-making mechanisms will work for the members of the coalition to make a joint decision, including majority voting. In our framework (because of the homogeneity of all participants), the result will be an action which maximizes the joint payoff of the coalition members. ${ }^{11}$ Furthermore, the coalition acts as one agent in a Nash game in contributions with the fringe.

More specifically, for a coalition of size $\mathrm{N}$, let $\Pi^{\mathrm{c}}(\mathrm{N})$ and $\Pi^{\mathrm{f}}(\mathrm{N})$ be the payoffs to a member of the coalition and the fringe, respectively, from the contributions stage game. These payoffs are a function of the size of the coalition only. Clearly, members of the fringe will always choose private consumption, with a payoff of 1 plus any payoff from public consumption by others $(\gamma \mathrm{Q})$. The coalition will choose public consumption if

$$
\Pi c(\mathrm{~N})=\gamma \mathrm{Q}=\gamma \mathrm{N} \geq 1 \Leftrightarrow \mathrm{N} \geq 1 / \gamma
$$

Conversely, if $\mathrm{N}<1 / \gamma$, coalition members will choose private consumption. Implicitly and arbitrarily, we assume that indifference between public and private consumption results in public consumption.

We now turn to the membership game. We are interested in a Nash equilibrium in announcements to be in either the fringe or the coalition. Using the terminology of cartel theory,

\footnotetext{
${ }^{11}$ Clearly, with heterogeneous agents, majority voting reflects the interests of the median voter and may not yield a joint payoff maximum. That issue is moot here since all agents are identical. With homogenous agents, majority rule, unanimity and joint payoff maximization are all equivalent.
} 
as well as the literature on international environmental agreements, this leads to the following definitions:

Definition 1: A coalition of size $\mathrm{N}$ is internally stable if $\Pi^{\mathrm{c}}(\mathrm{N})>\Pi^{\mathrm{f}}(\mathrm{N}-1)$.

Definition 2: A coalition of size $\mathrm{N}$ is externally stable if $\Pi^{\mathrm{f}}(\mathrm{N})>\Pi^{\mathrm{c}}(\mathrm{N}+1)$.

Definition 3: A coalition of size $\mathrm{N}$ is stable if it is externally and internally stable.

In other words, the coalition is internally stable if no individual wishes to leave to join the fringe; it is externally stable if no fringe member wants to join the coalition. In this linear framework, there is one and only one non-trivial stable coalition.

Let $\mathrm{N}^{*}$ be the Nash equilibrium in the membership game; i.e., the stable number of members of the coalition. It is useful to define one more simple function, the "rounding-up" function which rounds a real number up to an integer:

Definition 4: Define $\mathrm{I}(\mathrm{x})$ as the smallest integer greater than or equal to $\mathrm{x}$.

This leads to the following result:

Proposition 1. In a simple two-stage homogeneous membership-contributions game with payoffs as in Eqn. (1), the equilibrium number of members of the coalition is $\mathrm{N}^{*}=\mathrm{I}(1 / \gamma)$, which is the size of the stable coalition.

The intuition behind this proposition is that $\mathrm{N}^{*}$ is the minimum size of coalition which wishes to fully invest in the public investment. For any smaller coalition (such as $\mathrm{N}^{*}-1$ ), it is optimal to fully invest in the private good. Thus any coalition member is pivotal; departure from the coalition causes a significant change in payoffs, sufficient to provide an incentive not to depart. Similarly, there is no incentive for any fringe member to join the coalition since a coalition of size $\mathrm{N}^{*}+1$ continues to fully invest in the public good (Kolstad and Ulph, 2008). 
We can now introduce the notion of uncertainty in public good provision into the framework. Suppose there are two possible states of the world, high (H) and low (L), with probabilities $\pi$ and (1- $\pi$ ), respectively. Let $\gamma$ take on a value dependent on the state of the world: $\gamma_{\mathrm{H}}$ and $\gamma_{\mathrm{L}}$, in expectation simply $\gamma$. We assume that the state of the world is revealed between the two stages of the game; thus, in the membership game, agents are unaware of the state of the world but in the contributions game they do know the state of the world. This assumption is consistent with previous theory (Kolstad and Ulph 2008, Ulph 2004) and, to some extent, with real-world experiences. The decision to join a coalition is a strategic decision with longer-term consequences than the more tactical and short-term decision of how much to contribute to a public good. Strategic decisions may occur far in advance of tactical decisions as they in fact have on international agreements to provide public environmental goods. This characterization only provides intuition since this theoretical model is static.

Unfortunately, clear and unambiguous results on the effect of uncertainty are not available in the literature (see Kolstad and Ulph, 2008). This ambiguity suggests that it is an empirical question whether the coalition is larger or smaller under uncertainty.

We use the model above to lay out theory-based predictions and construct the experimental design we use to test those predictions. This model provides a standard result that the size of the coalition, $\mathrm{N}^{*}$, is equal to the smallest integer greater than the inverse of the ratio of costs to benefits. Based on a Nash equilibrium of zero contributions in an uncoordinated public goods game, we expect to see coalition size follow the theoretical prediction. However, given that public goods experiments consistently find non-Nash prediction levels, we will also be interested in systematic deviations from the theoretical $\left(\mathrm{N}^{*}\right)$ prediction. Additionally, we vary $\gamma$ 
across sessions, and this allows us to test whether coalition size decreases as $\gamma$ increases, as predicted by theory.

In more formal terms, the two hypotheses we consider are as follows:

i. The coalition mechanism increases contributions to the public good over the baseline treatment (standard public goods).

ii. Coalition size decreases as MPCR $(\gamma)$ increases.

iii.

Hypothesis (i) simply tests whether allowing coalitions makes any difference. Hypothesis (ii) tests the basic result in the theory (Prop. 1). Uncertainty has an ambiguous effect; thus theory does not suggest whether contributions should fall when we introduce uncertainty in the public goods treatment or the coalition formation treatment. In particular, standard theory predicts zero contributions with or without uncertainty, and we look to the lab to provide empirical guidance regarding the role of uncertainty.

\section{Experimental Design}

Our experimental design allows us to test the theoretical predictions outlined in the previous section. The experiment comprises four treatments: (1) a standard public goods game, (2) public goods with uncertainty, (3) public goods with coalition formation, and (4) coalition formation with uncertainty. We explain these four treatments in more detail below. Drawing on a pool of undergraduate and graduate students from the University of California, Santa Barbara, we recruited ten participants for each of eight experimental sessions $(n=10)$. Each session included the four treatments with twenty periods per treatment. In total, we have observations on 80 subjects and 640 periods. We conducted all experiments in a computer lab using the software $z$-Tree (Fischbacher 2007). Subjects received payment for participating at the rate of $\$ 0.01$ for 
each experimental monetary unit (EMU) earned during the experiment. ${ }^{12}$ Average earnings per subject were between $\$ 20-25$, and each session lasted approximately 90 minutes. Once subjects had completed all four treatments, we administered a brief questionnaire to gather demographic data for later analysis. After all subjects completed the questionnaire, we totaled subjects' earnings and paid them in cash.

Below we describe the four treatments in our experiment. For more detailed information, we provide a copy of the script used in all eight sessions in appendix A.

\subsection{Treatment 1: Public Goods}

The first treatment in our experiment is a standard public goods game with a voluntary contribution mechanism. This treatment provides a baseline with which to compare the effects of coalition formation and uncertainty. In each period, subjects receive an endowment of $w$ tokens that they must allocate to either a private investment or a public investment. ${ }^{13}$ The private investment returns one EMU at the end of the period, while the public investment provides a lower private return, the MPCR, but more in total to the group. The MPCR was 0.3 in sessions 13 and 7 and increased to 0.6 in the sessions 4-6 and 8. In other words, if all 10 subjects allocate their endowment to the public investment, each and every person receives $n * w * M P C R$ EMUs. Clearly, the Nash equilibrium in this game is to allocate zero tokens to the public investment whereas Pareto optimality requires all tokens be allocated to the public investment.

Deviating from most public goods experiments, we use a binary contribution mechanism. In other words, despite the fact that $w$ is not binary, subjects must allocate all or none of their endowment to the public investment each period. As explained in Section 3, the binary

\footnotetext{
${ }^{12}$ If earnings totaled less than $\$ 5$, the subject receives a $\$ 5$ minimum payment. This constraint was never biding.

${ }^{13}$ In the experimental script, we refer to these as a "private project" and "public project," respectively.
} 
mechanism more closely mirrors the established theory and simplifies the coalitions' allocation decision. ${ }^{14}$ However, some research has shown that binary contribution mechanisms result in lower public good provision levels than continuous contribution mechanisms (Cadsby \& Maynes 1999). While continuous contribution designs are more common, the binary mechanism allows the experimental design to more closely match the theory.

\subsection{Treatment 2: Public Goods with Uncertainty}

In treatment two the return on the public investment becomes uncertain. In each round there is a $1 / 3$ probability that the public investment will not pay out. If this occurs, all subjects receive a zero return on any contributions made to the public investment. Correspondingly, there is a $2 / 3$ probability that the public investment will pay out in full. In order to preserve the expected value of public investment returns, we increase the MPCR in the uncertainty treatments by 50 percent: sessions in which the initial MPCR was $0.3(0.6)$ offer an MPCR of $0.45(0.9)$ when public good provision is uncertain. In all other ways, this treatment is the same as treatment one.

\subsection{Treatment 3: Coalition Formation}

In treatment three we introduce the coalition formation mechanism as a modification to treatment one. Before making their investment decisions in each period, subjects must first elect to either join the coalition or remain in the fringe. Once subjects have formed the coalition, the software reports the coalition size to all subjects. In our theoretical model, the coalition uses

\footnotetext{
${ }^{14}$ In a theoretical environment, agents are homogenous, thus voting is unnecessary. In an experimental setting, however, agents are likely to have heterogeneous contribution preferences, either due to preferences that are not strictly rational or to simple errors in decision-making. While the voting mechanism departs from the theory, it is a necessary and pragmatic feature of the experiment.
} 
majority voting to determine the joint action. This approach is also used in the experimental design. If a majority of the coalition votes to contribute, the coalition's entire endowment is pooled and allocated to the public investment. If the majority votes not to contribute, then the coalition allocates its entire endowment to the private investment. ${ }^{15}$ To be as consistent with the theory as possible, the coalition cannot subdivide its collective endowment. In the event of a tie, a virtual coin flip determines the allocation decision. At the end of the period the coalition is reset and the next period begins with an "empty" coalition - coalition membership does not carry over between periods.

\subsection{Treatment 4: Coalition Formation with Uncertainty}

Treatment four combines the coalition formation mechanism with uncertainty in public goods provision. This treatment is similar to treatment three, except that subjects do not know whether the public investment will pay out when they make their decision to join the coalition. However, once the coalition has formed the software reports the "state of the world" to all subjects. In other words, before the coalition (as a whole) and the fringe (individually) make their allocation decision, all subjects are informed whether the public investment will return zero or $1.5^{*} \mathrm{MPCR}$ at the end of the period. The uncertainty in treatment four is resolved between the coalition formation stage and the public good allocation stage to be consistent with theory. ${ }^{16}$ Once again, the probability of non-provision is $1 / 3$. With the exception of the uncertainty element, this treatment is identical to treatment three.

\footnotetext{
${ }^{15}$ Because we are focusing on a public good — and not a club good—public investment contributions from both the coalition and the fringe determine the public investment return for all subjects, whether or not they are members of the coalition.

${ }^{16}$ Conditional on being in the coalition, subjects generally make the "correct" assessment of whether the coalition should contribute, with an error rate of approximately eight percent (voting to contribute when it is certain the public good will not payout). Subjects in the fringe made no errors of this kind.
} 
Our theory makes specific predictions about what size of coalition we should expect to observe in the case of certainty: an MPCR of 0.3 should produce a coalition of size four, while raising the return on the public good to 0.6 should reduce the coalition size to two.

\section{Results}

In this section we present two approaches to analyzing our data. We use both nonparametric and regression methods to analyze data from our experiments, recognizing the limitations of each. We begin with simple statistical tests of the hypotheses described in the previous section. Non-parametric analysis requires minimal statistical assumptions, but may not capture more subtle results. We then develop two regression models of group and individual behavior to further test our hypotheses.

\subsection{Summary of Experimental Results}

Subjects in our first treatment contributed to the public good at rates comparable those in most previous public goods experiments. Despite the Nash prediction that subjects will allocate zero tokens to the public good, we find contribution rates of between 50 and 70 percent in the initial periods. Contributions decline over time to between 20 and 30 percent by the end of each treatment. Figure 1 shows the pattern of contribution rates over time for treatment one, the standard public goods game with binary contributions. Because subjects must allocation all or none of their endowment, the time trend in Figure 1 is relatively volatile, even after averaging across sessions.

Figure 2 shows average coalition size over time in the coalition treatment and the coalition with uncertainty treatment. The size of a coalition is the number of individuals who 
elect to join in a given period. Recall that the coalition resets after each period, so coalition size is not a function of members "dropping out" per se. While coalition size exhibits a declining trend similar to contribution rates, there is a noticeable degree of stability between periods 5 and 15. In both treatments coalition size stabilizes after an initial decay and then falls as the subjects near the end of the treatment. However, there is no obvious difference in coalition size between the no-uncertainty and uncertainty treatments.

It is instructive to examine how subjects behaved in the different experimental sessions. Table 1 shows the mean contribution rates for each treatment across all eight sessions. Subjects contributed an average of 41.1 percent of their tokens to the public good in the standard public goods treatment, while rates declined to 38.9 percent when the public good provision was uncertain. In the coalition treatment, contribution rates increased to 48.1 percent but fell by seven percent when we introduced uncertainty.

While the above averages suggest a relatively consistent pattern across treatments, there is significant variability across sessions. It is possible that the variability in contributions is in part a function of the binary contribution mechanism. Although we cannot test this conjecture rigorously with our data, previous work on binary contribution mechanisms is consistent with highly variable contribution rates (e.g., Cadsby and Maynes 1999).

In our initial six sessions, we reversed the order of non-coalition and coalition treatments in sessions three and six. Concerned that the unusually low contribution rates in the public goods treatment in session three might be a result of order effects, we ran two additional sessions using the standard order described in section 3. However, as Table 1 shows, session seven has similar contribution rates as session three. Consequently, we see no obvious reason to exclude these data 
from our analysis. Excluding sessions three and six does not dramatically change the majority of our findings, thus we analyze all eight sessions of data in the remainder of the paper. ${ }^{17}$

Because varying the MPCR is important to our analysis, we consider the data for the high (0.6) and low (0.3) MPCR sessions separately. Table 2 provides a summary of the contribution rate and coalition size in each treatment for high and low MPCR sessions, averaged across all 20 periods in each treatment. Once again, contribution rates increase with the introduction of the coalition mechanism but decrease when public good provision is uncertain. As in previous experimental studies, a higher MPCR induces higher contribution rates.

The high MPCR sessions had dramatically larger average coalition sizes for both nouncertainty and uncertainty treatments, 5.1 in each. However, coalition size does not appear to vary systematically depending on whether or not the public good is uncertain. Average coalition size was 3.5 in the low-MPCR sessions with no uncertainty and slightly lower, 3.45 , under uncertainty.

\subsection{Statistical Analysis}

We now evaluate the statistical robustness of our results, using non-parametric tests on both session- and subject-level data. By using non-parametric tests we avoid making distributional assumptions that may not be warranted. Session averages are appealing because they constitute the only truly independent observations; however, the small sample-size $(\mathrm{N}=8)$ is limiting. Consequently, we also consider subject-level differences across treatments. Using a Wilcoxon signed-rank test, ${ }^{18}$ we cannot reject the null hypothesis that contribution rates are equal

\footnotetext{
${ }^{17}$ In subsequent analysis, we indicate when excluding these treatments affects our results.

${ }^{18}$ We use the Wilcoxon signed-rank test to non-parametrically test the equality of matched pairs of observations, where the observations are the averages across all periods either for sessions $(\mathrm{N}=8)$ or subjects $(\mathrm{N}=80)$. The test
} 
in the public goods treatments with and without uncertainty, either at the session (one-tailed, ${ }^{19} \mathrm{p}$ $=0.17$ ) or subject level (one-tailed, $\mathrm{p}=0.36$ ). However, we do find evidence that contribution rates fall in the coalition treatments with uncertainty using session-level data (one-tailed, $\mathrm{p}=$ 0.005). Subject-level data provide stronger results (one-tailed, $p=0.000$ ). Thus we find some support for the hypothesis that uncertainty reduces contribution rates.

We are also interested in whether the coalition mechanism increases average contribution rates over the simple public goods treatment. Comparing treatments one and three, we can only reject the null hypothesis of equal contribution rates in the public goods and coalition treatments at the ten-percent level (one-tailed, $\mathrm{p}=0.10) .{ }^{20}$ Using data at the subject level we find stronger support for the idea that the coalition mechanism raises contribution rates (one-tailed, $\mathrm{p}=0.005$ ). We also find evidence that the coalition mechanism increases contributions when the public good is uncertain (one-tailed, $\mathrm{p}=0.06$ ). Here the evidence is less-strong at the subject level (onetailed, $\mathrm{p}=0.15$ ). Overall, allowing subjects to form a coalition tends to increase the rate at which they contribute to the public good, as theory predicts.

Turning to the issue of coalition size, we are interested in the effect of MPCR and uncertainty on coalition size. Let the null hypotheses be that coalition size will (1) be unaffected by uncertainty and (2) fall as the MPCR rises. Our results confirm the former but refute the latter. Using a signed-rank test we cannot reject the null hypothesis that coalition size is equal across treatments with and without uncertainty at the session level (two-tailed, $\mathrm{p}=0.94$ ). The

takes into account both the direction ("sign") and magnitude ("rank") of the difference in pairs of outcomes for an observational unit.

${ }^{19}$ Because theory predicts the direction of the difference between treatments, we use a one-tailed test. To test on the effect of uncertainty on coalition size, where theory is ambiguous, we use a two-tailed test.

${ }^{20}$ This result is sensitive to excluding the "reverse order" treatments, three and six. Without these treatments we can only reject the null hypothesis at the 30 percent level for the session-level data, and the subject-level results are only slightly more significant. 
theory suggests uncertainty has an ambiguous effect on coalition membership, and the empirical results shed no additional light on the matter.

In contrast, we reject the null hypothesis of equal coalition size across low and high MPCR using Mann-Whitney test ${ }^{21}$ (one-tailed, $\mathrm{p}=0.030$ ) in favor of the alternative hypothesis, a positive effect of MPCR. In other words, an increase the MPCR increases coalition size, contrary to theory. We find similar evidence when public good provision is uncertain (one-tailed, $\mathrm{p}=0.042$ ). This result strongly contradicts hypothesis $i i i$ : we find that coalition size increases with MPCR. The pattern is clear in the data and statistically robust: a higher return on the public good tends to strengthen the coalition.

Tests of the differences across treatments suggest that a higher MPCR raises both contribution rate and coalition size. Additionally, the coalition mechanism tends to increase contribution rates. However, there is only weak evidence that uncertainty affects whether subjects contribute to the public good, and little evidence of an effect on coalition size.

Finally, we also ran all of these tests using only data from periods six through twenty. As is common in lab experiments, the first five periods have a higher degree of volatility, which may be due to subjects' unfamiliarity with the experiment. By dropping the first five periods, we consider the results of a more "stable" set of periods. In general, this exclusion has only a modest effect on our results, with p-values falling somewhat in most tests. For example, testing the effect of the coalition mechanism on contribution rates with no uncertainty, we can now reject the null using session-level data at the 0.03 significance level, where before we could only reject at the 0.10 level.

\footnotetext{
${ }^{21}$ The Mann-Whiteney test-also known as the Wilcoxon rank-sum test-is a non-parametric test of independent samples. Here we compare the average contribution rate for the high-MPCR sessions $(\mathrm{N}=4)$ to the rates for lowMPCR sessions $(\mathrm{N}=4)$. Again, as theory suggests that an increase in MPCR should reduce coalition size, we use a one-tailed test.
} 


\subsection{Group-level Analysis}

We use group-level regression techniques to control for both period and session fixed effects as we examine group-level behavior, where a group is the set of subjects in each session. The dependent variable is the per period average contribution rate, which we assume is a function of treatment effects and period. Our estimation equation is as follows rate $_{j k t}=\alpha+\beta_{1}($ uncert $)+\beta_{2}($ coalition $)+\beta_{3}($ mpcr_high $)+\gamma($ period block $)+\varepsilon_{j k t}$

$$
\begin{gathered}
\text { where } j=\operatorname{session}(2-8) \\
\qquad \begin{array}{c}
k=\text { treatment } \\
t=\text { period }
\end{array}
\end{gathered}
$$

The three variables of interest are uncert, coalition, and mpcr_high, which are dummy variables that indicate whether the public good was provided with uncertainty, whether the subjects had the option to form a coalition, and whether the mpcr was high, respectively. ${ }^{22}$ Our hypothesis is that $\beta_{1}<0$ and $\beta_{2}>0$. The variable period block is a set of three dummy variables for periods 5-10, 11-15, and $15-20 ;^{23}$ consequently, the coefficient vector $\delta$ captures the decay in contributions over time. We present the group-level regression results in Table 3 . We estimate (1) using a random effects estimator to account for session effects. ${ }^{24}$ In column $a$ we report results from a pooled regression, which includes data from both the high and low MPCR

\footnotetext{
${ }^{22}$ We tried including an interaction term, uncert ${ }^{*}$ coalition, to examine whether uncertainty plays a differential role in the coalition treatments, but this variable was not significant.

${ }^{23} \mathrm{We}$ use period-block dummies rather than individual period dummies to economize on space. Running all regressions with individual period dummies does not significantly change the results.

${ }^{24}$ The choice of random effects is appropriate because our other regressors - namely the treatment dummies — are by definition uncorrelated with the unobservable individual-specific term.
} 
sessions. The next two columns, $b$ and c, provide separate regression results for each MPCR level.

The group-level regression results support our initial findings. In the pooled regression, the coefficients on both the coalition ${ }^{25}$ and uncertainty variables are significant and of the predicted sign. Allowing subjects to form a coalition tends to increase the contribution rate by 4.9 percentage points, while uncertainty in the public investment tends to reduce contributions by 4.3 percentage points. The coefficient on the MPCR dummy is positive and significant, as expected. The coefficients on the period-block dummies are all negative and significant, which is consistent with the decay in contributions over time found in most public goods experiments (Ledyard 1995).

Regressions $b$ and $c$ are provide similar results as the pooled regression but reveal heterogeneity in the effect of coalition formation. For both high and low MPCR sessions, the coalition mechanism tends to increase contribution rates. However, the coalition coefficient in the high MPCR regression is roughly half the magnitude of low MPRC coefficient and not significant at the 10 percent level $(p=0.11)$. The effect of uncertainty in both the high and low MPCR sessions is consistent, and the coefficient is significant in each.

\subsection{The Effect of the Voting Mechanism}

One concern is that the voting mechanism - which we use to aggregate individual decisions - may have an independent effect on contribution rates. Research on voting suggests that allowing subjects to express their preference for (or against) a collective decision tends to increase public goods provision (Walker et al. 2000). Unfortunately, it is difficult to separately

\footnotetext{
${ }^{25}$ The significant coefficient on coalition formation is sensitive to discarding the data from our reverse order sessions (three and six). Excluding these data cause the coalition variable to become insignificant in the pooled and separate regressions.
} 
identify the effect of voting, as it is a preference aggregation mechanism necessary to implement a rule that constrains group or individual behavior. In other words, in the voting literature, experimental subjects are always voting for a particular rule-e.g., allocation (Walker et al. 2000), punishment (Feld and Tyran 2002), or expulsion (Cinyambuguma et al. 2005) - that may be the cause of elevated contributions. In this paper we use a fixed allocation rule, an all or nothing contribution scheme, which is binding for coalition members. The voting and coalition mechanisms are inherently linked.

Nevertheless, we can consider in part the consequences of voting in our experimental design. The theoretical model necessarily predicts unanimity among coalition members (due to homogeneous agents), but "real world" coalitions will likely suffer from internal dissent. Of the 314 periods in which a coalition formed, 172 (55 percent) resulted in a unanimous decision by the coalition members; using a supermajority voting criterion of 80 percent, 233 ( 74 percent) coalitions attained this level of agreement. Coalitions are not consistently unanimous as the theory predicts, but the level of agreement among members is high.

Finally, if we redo the analysis in Section 5.2 and exclude observations from treatments three and four in which the coalition did not reach a unanimous decision, the results (not reported) are unchanged. The coalition mechanism has a strong, positive effect on contribution rates, and if anything, the observed effects are stronger. Consequently, while non-unanimous voting decisions are not predicted by theory, they appear to have little effect on the experimental results.

\subsection{Individual-level Analysis}

In addition to analyzing group behavior, we can also look at individual-level choices. Again we use a random effects estimator, here to account for unobserved individual variation. 
This model includes session dummies to account for session effects. We estimate the following model:

$P\left(\right.$ allocation $\left._{j k t}=1 \mid x\right)=G\left(\alpha+\beta_{1}(\right.$ uncert $)+\beta_{2}($ coalition $)+\beta_{3}($ mpcr_high $)+\tau($ session $)+\gamma($ per. block $\left.)\right)$

$$
\begin{aligned}
& \text { where } i=\text { individual (80 subjects) } \\
& \qquad \begin{aligned}
j & =\operatorname{session}(2-8) \\
k & =\text { treatment } \\
t & =\text { period }
\end{aligned}
\end{aligned}
$$

Because we employ a binary contribution mechanism, our dependent variable is a dichotomous indicator that equals one if $i$ allocated her endowment to the public investment under treatment $k$ in period $t$, session $j$. We include the treatment variables along with period dummies as before.

Table 4 presents results based on equation (2). We have suppressed the coefficients period controls to conserve space. Column (a) reports the random effects LPM results. Due to the well-known limitations of LPM models, we turn to our preferred specification, a random effects probit model, in column (b). The final two columns, $c$ and $d$ in Table 4 report separate random effects probit results for the high/low MPCR sessions. All reported probit estimates are regression coefficients and not partial effects.

Once again, we find that being in the coalition treatment increases the likelihood that a subject contributes to the public investment, while uncertainty has the opposite effect. This result is consistent across pooled and non-pooled estimations in both the high and low MPCR cases. ${ }^{26}$ The LPM model indicates that an individual in a coalition treatment is 4.9 percent more likely to

\footnotetext{
${ }^{26}$ Excluding sessions three and six, we do not find a statistically significant result on the coalition variable in either the pooled or separate regressions.
} 
contribute to the public good. Conversely, in the uncertainty treatment subjects are approximately 4.3 percent less likely to contribute to the public good. The sign and significance of the probit results are qualitatively consistent with the LPM model, although the results should not be interpreted as marginal effects.

Lastly, because we collected some demographic data at the end of each session, we investigate any trends that emerge from the individual allocation results. While we do not report the detailed results here, we found that older individuals - mostly non-economics graduate students in our experiments - are more likely to contribute to the public good. Conversely, "experienced" students - those who have participated in previous experiments - tend to contribute less. Interestingly, women appear to contribute less than men, but this effect disappears once we control for age. Finally, economics students are no more or less likely to contribute than others.

\section{Conclusion}

Endogenous group formation is a growing area of research in experimental economics. And while the studies in this area are of high quality, few draw on theory to motivate experimental design. Conversely, there is a significant body of theoretical literature on the role of coalitions to provide public goods, especially in the context of international environmental agreements. Unfortunately, little of this theory has been tested. This study attempts to bridge these two research areas using experimental methods to test theoretical predictions of coalition formation.

The literature on international environmental agreements has developed simple models that generate clear hypotheses. Using a laboratory environment we are able to provide insight 
into whether these models accurately represent human behavior. Our results are mixed. We demonstrate that introducing a coalition mechanism can increase contributions to a public good, although this result is not as robust as some of our other findings. A stronger result is that while theory predicts an inverse relationship between coalition size and the return on the public good, we find the opposite. Doubling the MPCR from 0.3 to 0.6 increases coalition size by a statistically significant amount. From the perspective of public goods provision, this is a potentially promising finding. Existing theory states that coalitions are unlikely to form-and thus serve as an effective mechanism — when the benefits of public good provision are high. In fact, this study suggests coalitions may be more likely to form when they are most beneficial.

We believe this result is consistent with earlier experimental work on voluntary public goods provision. In most studies a higher MPCR induces subjects to contribute more to the public good, as contributions become more valuable. It appears that subjects respond in a similar fashion when deciding whether or not to join a coalition. It may be that at a higher MPCR the coalition mechanism — which offers the opportunity to induce others to contribute—-becomes more appealing. At the same time, it is important to acknowledge that we do not—at this timehave a good explanation for the divergence between theory and behavior in a laboratory setting. It is difficult to draw strong conclusions about our MPCR results when subjects behave contrary to theory even in a simple public goods game; this is an area that will require further research.

The role of uncertainty is also an important issue in the experimental and IEA literatures. Previous work by Dickinson (1998) uses an individual-level regression analysis and finds some evidence that subjects reduce their contributions rates when public goods provision is uncertain. We find additional support for this result. Even while maintaining the expected return on the 
public good, subjects reduced their contribution rates when we introduced uncertainty in public good provision.

A more pressing question in the international agreements literature is whether uncertainty strengthens or weakens coalitions. The relevance to environmental goods is clear: when the benefits of abatement are uncertain should we expect more or less cooperation to provide a public good? Here the theory is ambiguous: some argue that coalition size will increase in the presence of uncertainty, while others argue the opposite. Our experimental evidence does not support either of these hypotheses; uncertainty has little effect on coalition formation. This suggests an opportunity to refine existing theories of coalition formation under uncertainty and employ more robust empirical methods to test the resulting predictions. 
References

Ahn, T.K., Isaac, R.M., and Salmon, T.C. 2008. “Endogenous Group Formation.” Journal of Public Economic Theory. 10(2). p171-194.

Andreoni, James, "Cooperation in Public Goods Experiments: Kindness or Confusion?," Amer. Econ. Rev., 85:891-904 (1995).

Barrett, Scott. 1994. "Self-Enforcing International Environmental Agreements," Oxford Economic Papers. 46, p.878-94.

Berger, LA and Hershey, JC. 1994. "Moral Hazard, Risk Seeking, and Free Riding.” Journal of Risk and Uncertainty. 9. p173-186.

Bergstrom, T., Blume, L., and Varian, H. 1986. "On the Private Provision of Public Goods," Journal of Public Economics. 29. p.25-49.

Bernheim, B.D. 1986. "On the Voluntary and Involuntary Provision of Public Goods." American Economic Review. 76(4).

Bolton, G. and Chatterjee, K. 1996. "Coalition formation, communication and coordination: An exploratory experiment." In Eds. Zeckhauser, R.J. and Keeney, R.L. and Sebenius, J.K. Wise Choices: Games, Decisions, and Negotiations. Harvard Business School Press, p253-271.

Bottom, W.P., Holloway, J., McClurg, S., and Miller, G.J. 2000. "Negotiating a Coalition: Risk, Quota Shaving, and Learning to Bargain.” Journal of Conflict Resolution. 44(2). p147-169.

Cadsby, C.B. and Maynes, E. 1999. "Voluntary Provision of Threshold Public Goods with Continuous Contributions: Experimental Evidence.” Journal of Public Economics. 71(1).

Camerer, C. 2003. Behavioral Game Theory: Experiments in Strategic Interaction. Princeton: Princeton University Press.

Carraro, C. and Siniscalco, D. 1993. "Strategies for the International Protection of the Environment." Journal of Public Economics. 52(3).

Charness, G. and Yang, C.L.E.I. "Endogenous Group Formation and Public Goods Provision: Exclusion, Exit, Mergers, and Redemption.” Working Paper 2007.

Cinyabuguma, M., Page, T., and Putterman, L. 2005. "Cooperation Under the Threat of Expulsion in a Public Goods Experiment." Journal of Public Economics. 89, p1421-1435.

Dickinson, D.I. 1998. "The Voluntary Contributions Mechanism with Uncertain Group Payoffs." Journal of Economic Behavior \& Organization. 35, p517-533. 
Ehrhart, K., and Keser, C. "Mobility and Cooperation: On the Run." Working Paper. CIRANO. June 1999. http://ideas.repec.org/p/cir/cirwor/99s-24.html

Feld, L., and Tyran, J. 2002. "Tax Evasion and Voting: An Experimental Analysis." Kyklos 55(2), p197-221.

Fischbacher, U. 2007. “z-Tree: Zurich Toolbox for Ready-made Economic Experiments.” Experimental Economics. 10(2), p171-178.

Gunnthorsdottir, A., Houser, D., McCabe, K., and Ameden, H. 2007. "Disposition, History and Contributions in Public Goods Experiments." Journal of Economic Behavior and Organization. 62(2). p304-315.

Guth, W., Schmittberger, R., and Schwarze, B. 1982. “An Experimental Analysis of Ultimatum Bargaining.” Journal of Economic Organization and Behavior. 3, p367-388.

Hirschleifer, J. 1983. "From Weakest Link to Best Shot: The Voluntary Provision of Public Goods." Public Choice. 41(3).

Hoel, Michael. 1992. "International Environmental Conventions: The Case of Uniform Reductions of Emissions," Environmental and Resource Economics. 2, p41-59.

Iida, Keisuke. 1993. "Analytic Uncertainty and International Cooperation: Theory and Application to International Economic Policy Coordination," International Studies Quarterly. 37, p431-57.

Isaac, R.M. and Walker, J.M. 1988. "Group Size Effects in Public Goods Provision: The Voluntary Contributions Mechanism.” Quarterly Journal of Economics. 103(1).

Isaac, R.M., Walker, J.M. and Williams, A.W. 1994. "Group Size and the Voluntary Provision of Public Goods: Experimental Evidence Utilizing Large Groups." Journal of Public Economics. 54(1).

Kim, O. and Walker, M. 1984. “The Free Rider Problem: Experimental Evidence.” Public Choice. 43, p3-24.

Kolstad, C. 2007 "Systematic Uncertainty in Self-enforcing International Environmental Agreements.” Journal of Environmental Economics and Management. 53, p68-79.

Kolstad, C. and Ulph, A. "Uncertainty, Learning and Heterogeneity in International Environmental Agreements," Working Paper (2008).

Ledyard, J.O. 1995. "Public Goods" in Eds. John H Kagel and Alvin E. Roth The Handbook of Experimental Economics. Princeton: Princeton University Press. 
Marwell, G. and Ames, R.E. 1979. "Experiments on the Provision of Public Goods. I. Resources, Interest, Group Size, and the Free Rider Problem." American Journal of Sociology. 84(6).

Murnighan, J.K., Roth, A.E., and Schoumaker, F. 1988. "Risk Aversion in Bargaining: An Experimental Study." Journal of Risk and Uncertainty. 1, p101-124.

Okada, A., and Riedl, A. 2005. "Inefficiency and Social Exclusion in a Coalition Formation Game: Experimental Evidence." Games and Economic Behavior. 50, p278-311.

Page, T., Putterman, L., and Unel, B. 2005. "Voluntary Association in Public Goods Experiments: Reciprocity, Mimicry and Efficiency.” Economic Journal. 115, p1032-1053.

Roth, A.E. 1995. "Bargaining Experiments.” In Eds. Kagel, K.H. and Roth, A.E. The Handbook of Experimental Economics, Vol 1. Princeton University Press.

Sandler, T. \& Tschirhart, J. 1997. “Club Theory: Thirty Years Later.” Public Choice. 93, p335355.

Smith, V. 1980. "Experiments with a Decentralized Mechanism for Public Good Decisions." American Economic Review. 70, 584-599.

Ulph, Alistair. "Stable International Environmental Agreements with a Stock Pollutant, Uncertainty, and Learning." Journal of Risk and Uncertainty. 29(1), p53-73.

Young, Oran. 1994. International Governance: Protecting the Environment in a Stateless Society. Ithaca: Cornell University Press.

Walker, J.M., Gardner, R., Herr, A., and Ostrom, E. 2000. "Collective Choice in the Commons: Experimental Results on Proposed Allocation Rules and Votes." The Economic Journal. 110, p212-234. 
Figure 1: Average Contribution Rates (by period)

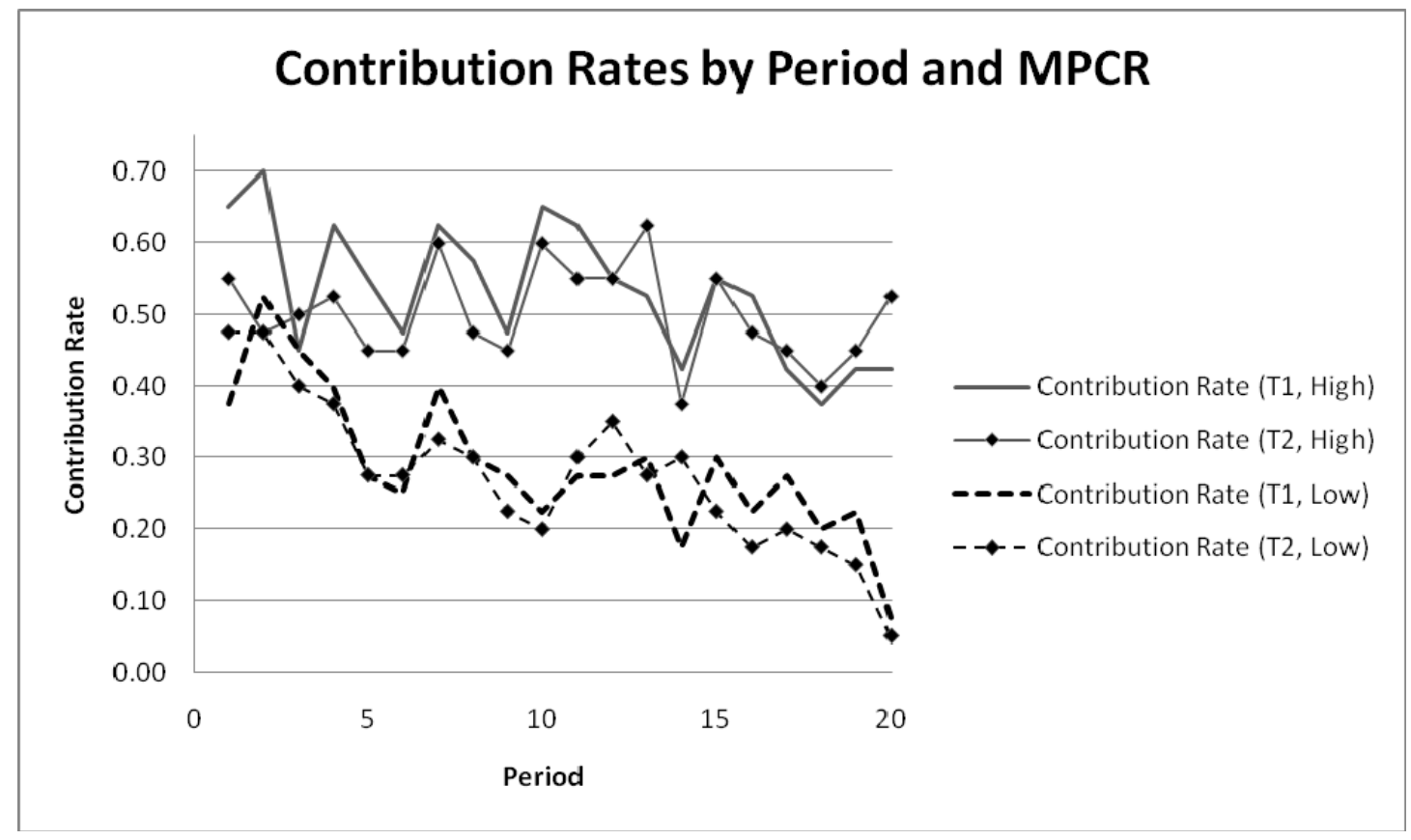

Figure 2: Average Coalition Size for Treatments 3 and 4 (by period)

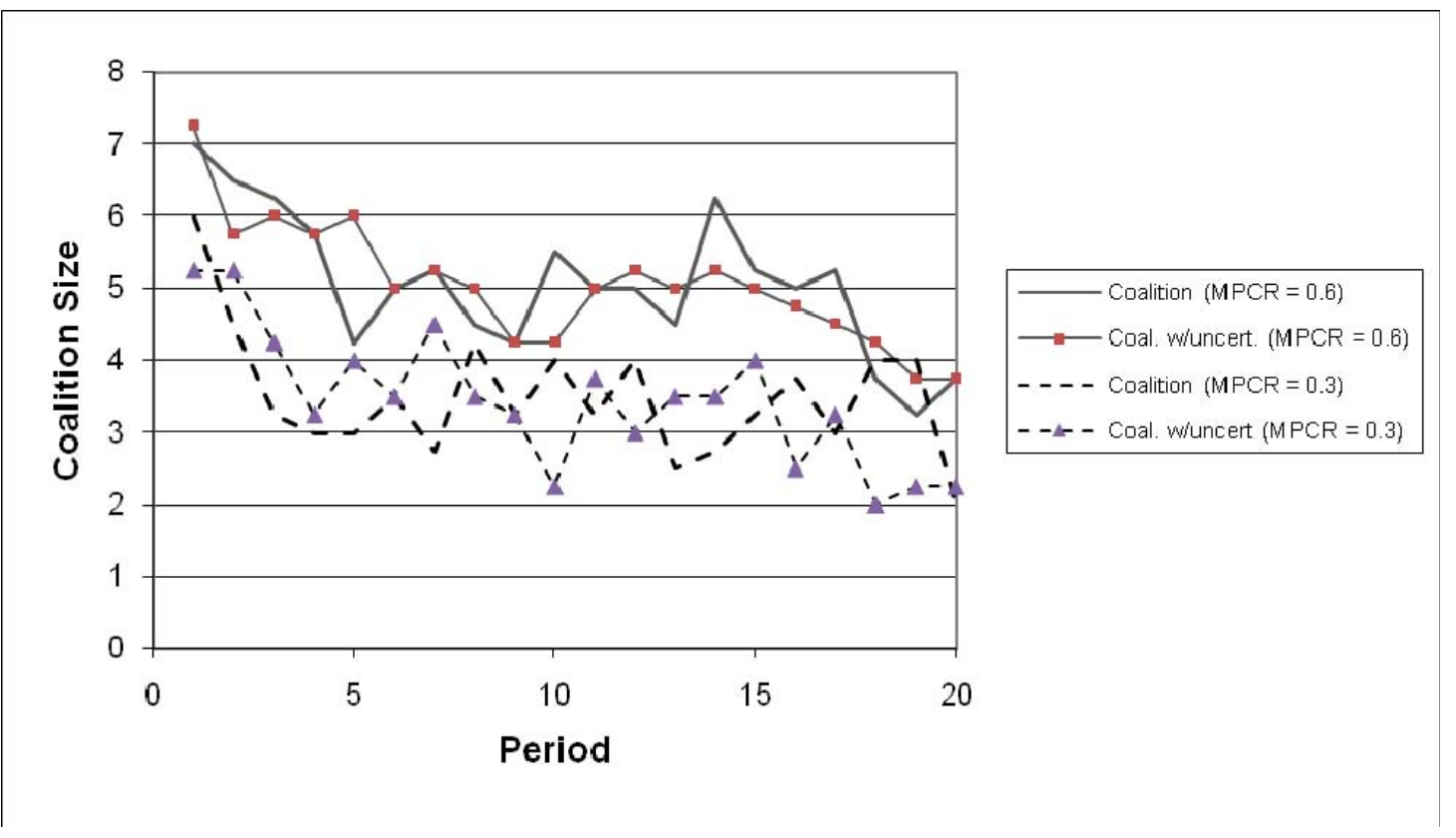


Table 1 - Mean Contribution Rates (\%) for Each Session (by treatment: T1, T2, T3, T4)

\begin{tabular}{|c|c|c|c|c|c|}
\hline Session & MPCR & T1: Public Goods & T2: PG w/uncert. & T3: Coalition & T4: Coalition w/uncert. \\
\hline 1 & 0.3 & 50.5 & 46.0 & 50.0 & 47.5 \\
\hline 2 & 0.3 & 40.0 & 35.5 & 29.0 & 26.5 \\
\hline $3^{*}$ & 0.3 & 14.5 & 14.0 & 49.5 & 30.5 \\
\hline 4 & 0.6 & 56.5 & 51.0 & 55.0 & 54.5 \\
\hline 5 & 0.6 & 54.0 & 41.5 & 56.0 & 43.0 \\
\hline $6^{*}$ & 0.6 & 44.0 & 44.5 & 54.5 & 46.0 \\
\hline 7 & 0.3 & 11.0 & 15.0 & 25.0 & 20.0 \\
\hline 8 & 0.6 & 58.0 & 63.5 & 66.0 & 65.0 \\
\hline Average & - & 41.1 & 38.9 & 48.1 & 41.6 \\
\hline
\end{tabular}

Notes: averages are across all 20 periods; * indicates reverse order session

Table 2 - Contribution Rates And Coalition Size Across MPCR Levels

\begin{tabular}{|c|c|c|c|c|c|}
\hline \multirow{3}{*}{ Treatment } & & \multicolumn{2}{|c|}{ Low MPCR } & \multicolumn{2}{|c|}{ High MPCR } \\
\hline & & Contribution & & Contribution & \\
\hline & & Rate & Coalition Size & Rate & Coalition Size \\
\hline \multirow[t]{2}{*}{ Public Goods } & mean & 0.290 & . & 0.531 & . \\
\hline & std. error & 0.025 & . & 0.018 & . \\
\hline \multirow[t]{2}{*}{ PG w/uncert. } & mean & 0.276 & . & 0.501 & . \\
\hline & std. error & 0.023 & . & 0.019 & . \\
\hline \multirow[t]{2}{*}{ Coalition } & mean & 0.384 & 3.500 & 0.579 & 5.063 \\
\hline & std. error & 0.027 & 0.189 & 0.017 & 0.159 \\
\hline \multirow{2}{*}{$\begin{array}{l}\text { Coalition } \\
\text { w/uncertainty }\end{array}$} & mean & 0.311 & 3.450 & 0.521 & 5.050 \\
\hline & std. error & 0.029 & 0.186 & 0.034 & 0.144 \\
\hline \multirow[t]{2}{*}{ Total } & mean & 0.315 & 3.225 & 0.533 & 5.242 \\
\hline & std. error & 0.013 & 0.132 & 0.012 & 0.107 \\
\hline
\end{tabular}

Notes: Contribution rates are averages across all periods and all participants for the low and high MPCR sessions by treatment. 
Table 3 - Group Level Regressions

Dependent variable is the per-period contribution rate

\begin{tabular}{lccc}
\hline & $(\mathrm{a})$ & $(\mathrm{b})$ & $(\mathrm{c})$ \\
& Pooled & $\mathrm{MPCR}=0.3$ & $\mathrm{MPCR}=0.6$ \\
\hline Coaltion & $0.049^{\star \star}$ & $0.064^{\star \star}$ & 0.034 \\
& $(3.20)$ & $(2.93)$ & $(1.59)$ \\
Uncertainty & $-0.043^{\star \star}$ & $-0.043^{\star}$ & -0.044 \\
& $(-2.83)$ & $(-1.96)$ & $(-2.06)^{\star}$ \\
MPCR (high) & $0.218^{\star \star}$ & - & - \\
& $(2.95)$ & - & - \\
Period Group 2 & $-0.073^{\star \star}$ & $-0.108^{\star \star}$ & -0.038 \\
& $(-3.15)$ & $(3.50)$ & $(-1.11)$ \\
Period Group 3 & $-0.056^{\star}$ & $-0.121^{\star \star}$ & 0.010 \\
& $(-2.56)$ & $(-3.72)$ & $(0.36)$ \\
Period Group 4 & $-0.158^{\star \star}$ & $-0.195^{\star \star}$ & $-0.120^{\star \star}$ \\
& $(-7.16)$ & $(-6.25)$ & $(-3.95)$ \\
Constant & $0.384^{\star \star}$ & $0.411^{\star \star}$ & $0.575^{\star \star}$ \\
& $(6.97)$ & $(6.14)$ & $(15.30)$ \\
\hline Observations & 640 & 320 & 320 \\
$\mathrm{R}^{2}$ (overall) & 0.26 & 0.11 & 0.08 \\
\hline Robust Z-satstics
\end{tabular}

Robust z-statistics in parentheses

* significant at 5\%; ** significant at $1 \%$ 
Dependent variable is contribution decision

\begin{tabular}{|c|c|c|c|c|}
\hline & $\begin{array}{c}\text { (a) } \\
\text { Rnd Effects }\end{array}$ & $\begin{array}{c}\text { (b) } \\
\text { RE Probit }\end{array}$ & $\begin{array}{c}\text { (c) } \\
\text { RE Pro (low) }\end{array}$ & $\begin{array}{c}\text { (d) } \\
\text { RE Pro (high) } \\
\end{array}$ \\
\hline Coalition & $\begin{array}{c}0.049^{\star \star} \\
(4.82)\end{array}$ & $\begin{array}{c}0.177^{\star \star} \\
(4.88)\end{array}$ & $\begin{array}{c}0.244^{\star \star} \\
(4.64)\end{array}$ & $\begin{array}{c}0.116^{\star \star} \\
(2.29)\end{array}$ \\
\hline Uncertainty & $\begin{array}{c}-0.043^{\star \star} \\
(-4.27)\end{array}$ & $\begin{array}{c}-0.172^{\star \star} \\
(-4.73)\end{array}$ & $\begin{array}{c}-0.171^{\text {}} \\
(-3.25)\end{array}$ & $\begin{array}{c}-0.165^{\star \star} \\
(-3.25)\end{array}$ \\
\hline Session 2 & $\begin{array}{l}0.050 \\
(0.64)\end{array}$ & $\begin{array}{c}-0.032 \\
(-0.16)\end{array}$ & $\begin{array}{l}-0.543 \\
(-1.49)\end{array}$ & $\begin{array}{l}- \\
-\end{array}$ \\
\hline Session 3 & $\begin{array}{c}-0.288^{\star \star} \\
(-3.99)\end{array}$ & $\begin{array}{c}-0.807^{\star \star} \\
(-3.87)\end{array}$ & $\begin{array}{l}-0.638^{\star} \\
(-1.76)\end{array}$ & $\begin{array}{l}- \\
-\end{array}$ \\
\hline Session 4 & $\begin{array}{c}0.375^{\star \star} \\
(5.78)\end{array}$ & $\begin{array}{c}0.551^{\star *} \\
(2.66)\end{array}$ & $\begin{array}{l}- \\
-\end{array}$ & - \\
\hline Session 5 & $\begin{array}{c}0.288^{\star *} \\
(4.10)\end{array}$ & $\begin{array}{c}0.851^{\star \star} \\
(3.93)\end{array}$ & $\begin{array}{l}- \\
-\end{array}$ & $\begin{array}{l}-0.269 \\
(-0.64)\end{array}$ \\
\hline Session 6 & $\begin{array}{c}0.375^{\star *} \\
(5.82)\end{array}$ & $\begin{array}{c}1.262^{\star \star} \\
(5.28)\end{array}$ & $\begin{array}{l}- \\
-\end{array}$ & $\begin{array}{l}-0.341 \\
(-0.80)\end{array}$ \\
\hline Session 7 & $\begin{array}{c}-0.488^{\star \star} \\
(-8.19)\end{array}$ & $\begin{array}{c}-0.642^{\star \star} \\
(-3.12)\end{array}$ & $\begin{array}{c}-0.970 * \star \\
(-2.67)\end{array}$ & - \\
\hline Session 8 & $\begin{array}{l}0.150^{\star} \\
(1.94)\end{array}$ & $\begin{array}{c}-0.066 \\
(-0.33)\end{array}$ & $\begin{array}{l}- \\
-\end{array}$ & $\begin{array}{l}0.244 \\
(0.58)\end{array}$ \\
\hline Period Group 2 & $\begin{array}{c}-0.073^{\star \star} \\
(-4.92)\end{array}$ & $\begin{array}{c}-0.261^{\star *} \\
(-5.13)\end{array}$ & $\begin{array}{c}-0.380^{\star *} \\
(-5.24)\end{array}$ & $\begin{array}{c}-0.140 * \star \\
(-1.96)\end{array}$ \\
\hline Period Group 3 & $\begin{array}{c}-0.056^{\star \star} \\
(3.81)\end{array}$ & $\begin{array}{c}-0.195^{\star \star} \\
(-3.82)\end{array}$ & $\begin{array}{c}-0.428^{\star \star} \\
(-5.90)\end{array}$ & $\begin{array}{c}0.037 \\
(0.51)\end{array}$ \\
\hline Period Group 4 & $\begin{array}{c}-0.158^{\star \star} \\
(-10.88)\end{array}$ & $\begin{array}{c}-0.572^{\star \star} \\
(-11.00)\end{array}$ & $\begin{array}{c}-0.727^{\star \star} \\
(-9.64)\end{array}$ & $\begin{array}{c}-0.422^{\star *} \\
(-5.88)\end{array}$ \\
\hline Constant & $\begin{array}{c}0.554^{\star \star} \\
(6.67) \\
\end{array}$ & $\begin{array}{l}0.105 \\
(0.37) \\
\end{array}$ & $\begin{array}{l}0.204 \\
(0.77) \\
\end{array}$ & $\begin{array}{l}0.291 \\
(0.96) \\
\end{array}$ \\
\hline $\begin{array}{l}\text { Observations } \\
\text { log-likelihood }\end{array}$ & $\begin{array}{c}6400 \\
-\end{array}$ & $\begin{array}{c}6400 \\
-3285.96\end{array}$ & $\begin{array}{c}3200 \\
-1579.56\end{array}$ & $\begin{array}{c}3200 \\
-1693.73\end{array}$ \\
\hline $\mathrm{R}^{2}$ & 0.09 & - & - & - \\
\hline
\end{tabular}

